\title{
Correction: Intracellular trafficking of adeno-associated virus (AAV) vectors: challenges and future directions
}

\author{
Jalish M. Riyad (D) - Thomas Weber
}

Published online: 26 March 2021

(c) The Author(s), under exclusive licence to Springer Nature Limited 2021

Correction to: Gene Ther

https://doi.org/10.1038/s41434-021-00243-z

After publication the authors noticed that a section of their paper was incorrect, thus a correction needed to be made to fix this.

The original section: Strikingly, replacement with the cytoplasmic tail of the cation-independent mannose 6phosphate receptor (ciMPR) failed to restore the function of AAVR in AAV2 transduction [50]. This appears to be remarkable, since the ciMPR is known to travel to the TGN via late endosomes $[80,81]$. However, the main function of the ciMPR is to deliver lysosomal proteins, which carry a mannose 6-phosphate, to the lysosomes. This transport is known to depend on the cytoplasmic tail of ciMPR [82]. These data are consistent with a model in which an AAVR mutant with the cytoplasmic tail of the ciMPR delivers the AAV particles to the lysosomes where they are degraded.

Has now been replaced with the following: The cationindependent mannose 6-phosphate receptor (ciMPR), on the other hand, is known to travel to the TGN $[80,81]$ and the endolysosomal system [82]. Accordingly, replacement of the C-terminal tail of AAVR with the cytoplasmic tail of the ciMPR targets AAVR to the Golgi and almost completely restores AAV2 transduction in AAVR knockout cells [50]. 